\title{
Investigation of Heat Insulation Performance of Hollow Clay Bricks Filled with Perlite
}

\author{
M. ARici*, B. Yilmaz And H. Karabay \\ Kocaeli University, Engineering Faculty, Mechanical Engineering Department, 41380 Kocaeli, Turkey \\ In this study, the possibility of enhancing heat insulation performance of hollow bricks by filling the cavities \\ with perlite is investigated. A conjugate heat transfer by conduction, convection and radiation in different hollow \\ bricks are analyzed numerically to assess their thermal performance. Calculations are performed for three scenarios \\ for each type of hollow brick: (i) cavities are filled with air, (ii) half of the cavities are filled with perlite while \\ the other half is filled with air, (iii) all cavities are filled with perlite. The benefit of filling cavities with perlite is \\ justified quantitatively for each investigated hollow brick type. It is concluded that the enhancement in insulation \\ performance can be up to $15.6 \%$ and $27.5 \%$ for half-perlite and full-perlite cases, respectively, depending on the \\ brick type.
}

DOI: 10.12693/APhysPolA.130.266

PACS/topics: 88.05.Sv, 44.10. $+\mathrm{i}, 44.25 .+\mathrm{f}, 44.40 .+\mathrm{a}$

\section{Introduction}

Energy consumption has been increasing rapidly worldwide as well as in Turkey due to strong growth in population and industrialization. Buildings are responsible for about $40 \%$ of total energy consumption and onethird of greenhouse emissions in the world [1]. Therefore it has become essential to implement legislation to reduce energy consumption through the buildings in countries such as Turkey which imports more than half of the energy need. Turkey adopted TS 825 - The National Standard of Thermal Insulation Requirements for Buildings and recently has begun to comply with European legislation on buildings, including Building Energy Performance Regulation. However, $U$-value of the new buildings constructed according to the recent regulations in Turkey is much higher than that of proposed by EU countries [2]. Pure thermal performance of building envelope structure is the main cause of energy consumption in buildings. In a typical house, external walls account for approximately $30 \%$ of total heat loss which requires an effort to improve heat insulation performance of each wall components. The primary concern of this study is the thermal performance of hollow bricks which are widely used in building facades.

Heat is transferred through bricks by conduction in solid joints and by convection and radiation in air filled cavities. Heat insulation performance of bricks can be enhanced by eliminating or reducing each of these heat transfer modes separately or simultaneously if possible. For instance, cavities of bricks can be configured in such a way to suppress convection [3-5], covering the internal surface of the enclosures with low emissivity coating to reduce radiation $[6,7]$ or filling the cavities with insulation or low conductive materials to eliminate both convection and radiation simultaneously [8-10].

In this study, the possibility of using perlite in hollow bricks to enhance heat insulation performance is investigated. Therefore, a conjugate heat transfer by conduction, convection and radiation in different hollow bricks filled with perlite are analyzed numerically to assess their performance. The benefit of filling cavities with perlite is justified quantitatively for each investigated hollow brick type.

\section{Investigated hollow bricks}

Four different clay hollowed brick geometries produced and widely used in the construction sector in Turkey are selected for the investigation. Type- $\mathrm{C}$ and type-D are considered as insulation bricks. The dimensions of the selected geometries are presented in Table I. Cross-section

TABLE I

Investigated hollow brick types.

\begin{tabular}{c|c|c|c|c}
\hline \hline Type & $\begin{array}{c}\text { Length } \\
{[\mathrm{cm}]}\end{array}$ & $\begin{array}{c}\text { Heigth } \\
{[\mathrm{cm}]}\end{array}$ & $\begin{array}{c}\text { Width } \\
{[\mathrm{cm}]}\end{array}$ & $\begin{array}{c}\text { Void fraction } \\
{[\%]}\end{array}$ \\
\hline $\mathrm{A}$ & 13.5 & 19 & 19 & 55.4 \\
$\mathrm{~B}$ & 29 & 13.5 & 19 & 53.3 \\
$\mathrm{C}$ & 15 & 23.5 & 24 & 53.4 \\
$\mathrm{D}$ & 24 & 23.5 & 24 & 48.0
\end{tabular}

views of the bricks are presented in Fig. 1. Calculations are carried out for three scenarios for each type hollow brick: (i) cavities are filled with air, (ii) half of the cavities are filled with perlite symmetrically so that center of gravity of brick will not change, (iii) all cavities are filled with perlite. Hereinafter, these three scenarios are defined as air, half-perlite, and full-perlite, respectively. Computations are also carried out for excluding and including radiative heat transfer in the calculations. Calculations are performed as two-dimensional. Thus, height of bricks is not considered in analyses. A cross-section of each brick which is employed for the present numerical calculations is given in Fig. 1 for the half-perlite scenario. In the figure, cavities filled with perlite are shown hatched while non-hatched cavities show air. 


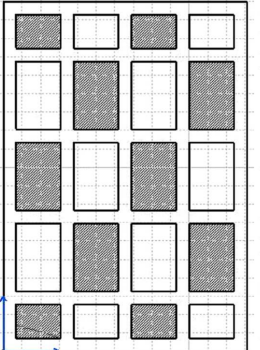

Type - A

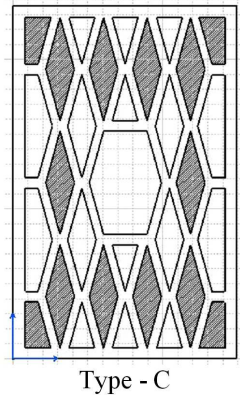

Fig. 1. Cross-section views of investigated hollow bricks with half-filled perlite.

\section{Mathematical model and numerical approach}

Thermophysical properties of porous clay, perlite, and air are given in Table II. All properties are assumed to be constant except the density of air which is responsible for the onset of convection due to buoyancy force. The Boussinesq approximation is employed to take into account the thermal buoyancy effects. It is considered that the flow in the holes is two-dimensional, steady-state, incompressible and laminar. It is reported in [11] that when the indoor-outdoor temperature difference varies from $20^{\circ} \mathrm{C}$ to $50^{\circ} \mathrm{C}$, the equivalent thermal conductivity of the investigated 72 kinds of hollow bricks does not vary considerably, usually within $\pm 5 \%$. Therefore, it is assumed that the left and right surfaces of the bricks are maintained at $20^{\circ} \mathrm{C}$ and $0{ }^{\circ} \mathrm{C}$ constant uniform temperatures, respectively, while bottom and top surfaces are insulated.

TABLE II

Thermophysical properties.

\begin{tabular}{c|c|c|c|c|c}
\hline \hline Materials & $\begin{array}{c}\rho \\
{\left[\mathrm{kg} / \mathrm{m}^{3}\right]}\end{array}$ & $\begin{array}{c}c_{p} \\
{[\mathrm{~J} / \mathrm{kg} \mathrm{K}]}\end{array}$ & $\begin{array}{c}\mathrm{k} \\
{[\mathrm{W} / \mathrm{m} \mathrm{K}]}\end{array}$ & $\begin{array}{c}\mu \\
{[\mathrm{kg} / \mathrm{m} \mathrm{s}]}\end{array}$ & $\begin{array}{c}\beta \\
{[1 / \mathrm{K}]}\end{array}$ \\
\hline $\begin{array}{c}\text { air } \\
\text { porous } \\
\text { clay } \\
\text { perlite }\end{array}$ & 1.246 & 1006 & 0.0244 & $1.802 \times 10^{-5}$ & $3.53 \times 10^{-3}$ \\
1600 & 1000 & 0.47 & - & - \\
& 120 & 800 & 0.046 & - & -
\end{tabular}

Based on the assumptions given above, governing equations are given as follows:

$$
\begin{aligned}
& \frac{\partial u}{\partial x}+\frac{\partial v}{\partial y}=0, \\
& u \frac{\partial u}{\partial x}+v \frac{\partial u}{\partial y}=-\frac{1}{\rho} \frac{\partial P}{\partial x}+\nu\left(\frac{\partial^{2} u}{\partial x^{2}}+\frac{\partial^{2} u}{\partial y^{2}}\right),
\end{aligned}
$$

$$
\begin{aligned}
& u \frac{\partial v}{\partial x}+v \frac{\partial v}{\partial y}=\nu\left(\frac{\partial^{2} u}{\partial x^{2}}+\frac{\partial^{2} u}{\partial y^{2}}\right)-g \beta\left(T-T_{\infty}\right), \\
& u \frac{\partial T}{\partial x}+v \frac{\partial T}{\partial y}=\alpha\left(\frac{\partial^{2} T}{\partial x^{2}}+\frac{\partial^{2} T}{\partial y^{2}}\right) .
\end{aligned}
$$

The governing equations are solved iteratively by using a commercial CFD code, ANSYS Fluent 15.0. Convective terms in momentum and energy equations are discretized by second order upwind scheme. Pressure and velocity terms are coupled through SIMPLE algorithm. The pressure term is discretized using body force weighted scheme. Radiation between the surfaces of cavities are taken into account using the surface to surface (S2S) radiation model which assumes that air in the cavity is non-participating medium for radiation. Emissivity of the cavity surfaces is assumed to be 0.9. No slip boundary condition is imposed on the walls of the cavities. A uniform structured grid is used in the solid parts of the bricks while a nonuniform structured grid is generated for the fluid regions in order to resolve velocity gradients near the solid wall. A systematic decrease in the grid size was employed to determine an optimum grid size. Careful examination of the results of the grid refinement study showed that the number of grid nodes varies between 87769 to 140452 depending on the hollow brick type to obtain a grid independent result.

\section{Results and discussions}

Hollow bricks consist of the solid part of clay and the cavities containing either air or perlite. Thus, effective thermal conductivity $\left(k_{\text {eff }}\right)$, which is defined in Eq. (5), should be used to determine their insulation performance

$$
k_{\text {eff }}=\frac{Q L}{A \Delta T},
$$

where $Q$ is the heat transfer rate through the brick, $L$ is the thickness of the brick, $A$ is the heat transfer area of the brick and $\Delta T$ is the temperature difference between the brick surfaces. Calculations are performed for excluding and including radiation heat transfer into calculation for the cavities containing air and obtained results are presented in Table III. As seen in the table, including radiation increases $k_{\text {eff }}$ very considerably. As seen in the table, radiation plays a significant role in the heat transfer in the cavities where the increase in $k_{\text {eff }}$ by including radiation is at least $35.9 \%$. Therefore, radiation has been taken into account for the subsequent calculations.

TABLE III

Effect of radiation on the effective thermal conductivity.

\begin{tabular}{c|c|c|c}
\hline \hline $\begin{array}{c}\text { Brick } \\
\text { type }\end{array}$ & $\begin{array}{c}\text { Excluding } \\
\text { radiation }\end{array}$ & $\begin{array}{c}\text { Including } \\
\text { radiation }\end{array}$ & $\begin{array}{c}k_{\text {eff }} \text { increasing } \\
\text { rate }\end{array}$ \\
\hline A & 0.187 & 0.257 & $37.7 \%$ \\
B & 0.182 & 0.247 & $35.9 \%$ \\
C & 0.102 & 0.166 & $62.5 \%$ \\
D & 0.131 & 0.193 & $47.8 \%$
\end{tabular}

The efficiency of bricks by filling the cavities with perlite is defined as 


$$
\begin{aligned}
& k_{\text {eff }} \text { reduction }(\%)= \\
& \quad\left(\frac{k_{\text {eff }} \text { with air }-k_{\text {eff }} \text { with perlite }}{k_{\text {eff }} \text { with air }}\right) \times 100 .
\end{aligned}
$$

Table IV compares the $k_{\text {eff }}$ of the investigated bricks for different scenarios of filling cavities. For the case of halfperlite, $k_{\text {eff }}$ reduces considerably particularly for type-A and type-B bricks which have relatively higher $k_{\text {eff }}$ values. For the case of full-perlite, the efficiency of bricks increases even further, as expected, since heat is transferred only by conduction through the brick. The minimum decrease in $k_{\text {eff }}$ is observed in type-D, which is $20.0 \%$. The reduction is more profound in other types of brick which is around $26-28 \%$. It is interesting to note that $k_{\text {eff }}$ value of type-A and type-B with full-perlite is lower than that of type-D with air.

TABLE IV

Effect of filling the cavities with perlite on the $k_{\text {eff }}$ of the investigated bricks.

\begin{tabular}{c|c|c|c|c|c}
\hline \hline $\begin{array}{c}\text { Brick } \\
\text { type }\end{array}$ & Air & $\begin{array}{c}\text { Half- } \\
\text {-perlite }\end{array}$ & $\begin{array}{c}k_{\text {eff }} \\
\text { reduction [\%] }\end{array}$ & $\begin{array}{c}\text { Full- } \\
\text {-perlite }\end{array}$ & $\begin{array}{c}k_{\text {eff }} \\
\text { reduction [\%] }\end{array}$ \\
\hline A & 0.257 & 0.217 & 15.6 & 0.188 & 26.8 \\
B & 0.247 & 0.210 & 15.0 & 0.181 & 26.7 \\
C & 0.166 & 0.148 & 10.9 & 0.120 & 27.5 \\
D & 0.193 & 0.173 & 10.6 & 0.155 & 20.0
\end{tabular}

\section{Conclusions}

In this study, the feasibility of filling hollow brick cavities with perlite is investigated in order to improve heat insulation performance. Therefore, heat transfer through various hollow bricks, which are widely used in Turkey, is analyzed numerically. Calculations are carried out for three scenarios for each type of hollow brick: (i) cavities are filled with air, (ii) half of the cavities are filled with perlite while the other half with air, (iii) all cavities are filled with perlite. The computed results show that filling the cavities with perlite inhibits convection and radiation in cavities. Hence effective thermal conductivity thus heat loss (or heat gain) reduces significantly for all types of brick. The enhancement in heat insulation performance can be up to $15.6 \%$ and $27.5 \%$ for halfperlite and full-perlite cases, respectively, depending on the brick type. It is concluded that since filling the cavities of hollow bricks with perlite provide a high potential of reducing effective conductivity, it should be considered by engineers to build residential or office buildings with low energy consumption.

\section{References}

[1] A. Sharma, A. Saxena, M. Sethi, V. Shree, Varun, Renew. Sustain. En. Rev. 15, 871 (2011).

[2] T. Kazanasmaz, İ.E. Uygun, G.G. Akkurt, C. Turhan, K.E. Ekmen, En. Build. 72, 38 (2014).

[3] L.P. Li, Y.G. Wu, Z.Y. Li, Y.L. He, W.Q. Tao, Int. J. Heat Mass Transf. 51, 3669 (2008).

[4] K. Arendt, M. Krzaczek, J. Florczuk, Int. J. Thermal Sci. 50, 1543 (2011).

[5] M.P. Morales, M.C. Juarez, P. Munoz, J.A. Gomez, En. Build. 43, 2494 (2011).

[6] M.A. Antar, Energy 35, 3508 (2010).

[7] P. Principi, R. Fioretti, En. Build. 51, 131 (2012).

[8] M. Zukowski, G. Haese, En. Build. 42, 1402 (2010).

[9] A. Sariisik, G. Sariisik, Mater. Struct. 45, 1345 (2012).

[10] Z. Pavlik, M. Jerman, J. Fort, R. Cerny, Int. J. Thermophys. 36, 557 (2015).

[11] L.P. Li, Z.G. Wu, Y.L. He, G. Lauriat, W.Q. Tao, En. Build. 40, 1790 (2008). 